\title{
An Exploratory Survey of Sound Levels in New York City Restaurants and Bars
}

\author{
Gregory Scott \\ Sound Print, New York, NY, USA \\ Email: greg@soundprint.co
}

How to cite this paper: Scott, G. (2018) An Exploratory Survey of Sound Levels in New York City Restaurants and Bars. Open Journal of Social Sciences, 6, 64-84. https://doi.org/10.4236/jss.2018.68005

Received: May 27, 2018

Accepted: August 7, 2018

Published: August 10, 2018

Copyright $\odot 2018$ by author and Scientific Research Publishing Inc. This work is licensed under the Creative Commons Attribution International License (CC BY 4.0).

http://creativecommons.org/licenses/by/4.0/

\begin{abstract}
For several decades, there has been a significant need to better educate the public about noise pollution. A small number of small-scale studies have focused on the sound levels of restaurants and their impact on health and hearing. There have also been an increasing number of media articles stating that eating and drinking venues are getting increasingly loud making it more difficult for people to connect with others in conversation. This study reports on an exploratory large-scale noise survey of sound levels of 2376 restaurants and bars in New York City using a novel smart-phone application and categorized them based on how quiet or loud they were. The results suggest that: 1) A significant number of venues have high sound levels that are not conducive to conversation and may be endangering the health of patrons and employees, 2) that the reported sound levels by the venue managers on their online public business pages generally underestimated actual sound levels, and 3) the average sound levels in restaurants and bars are correlated by neighborhood and type of cuisine.
\end{abstract}

\section{Keywords}

Restaurant, Noise, Quiet, Health, Hearing Loss

\section{Introduction}

Noise pollution is a widespread issue that a plethora of studies, both in the United States and abroad, have addressed. A small number of these studies have focused on the sound levels of restaurants and the impact of noise on health and hearing. There have also been an increasing number of media articles from several cities stating that eating and drinking establishments are getting increasingly loud either because of background music or architectural design that enhances rather than abates interior sounds [1]-[12]. 
This trend of increased noise can be attributed to modern design changes that are viewed as creating an exciting and bustling atmosphere [13]. This translates into more open kitchens, stripped-down or hard surfaces such as wooden floors, more windows, less tablecloths, no carpeting and fewer plants and paneling which help absorb sound. High table density with people in close proximity to one another and background music are also large contributors. There are also financial incentives for venue managers to produce higher sound levels since studies show that it causes people to drink more and eat faster, generating greater table turnover [14] [15] [16].

High sound levels in restaurants and bars can negatively impact the health and quality of life of patrons and employees as hearing loss is the third most common chronic physical condition in the US [17], and noise is the most common "modifiable environmental cause" of hearing loss which is present in $24 \%$ of adults [18]. Noise is also associated with tinnitus, a noise or ringing in the ears, which affects approximately $11 \%$ of adults and hyperacusis, an increased sensitivity to sound, which affects approximately 6\% of adults [19] [20] [21]. Research also shows that noise can contribute to exhaustion and also release cortisol in the body as it is linked to increased stress [22] [23], hypertension, ischaemic heart disease, stroke [24] and obesity [25].

A recent study showed that a large number of U.S. adults may be exposed to noise levels above the EPA recommended daily noise dosage limit of $70 \mathrm{dBA}$ [26]. And another study of more than 4500 adults in New York City suggested that nine out of ten adults exceeded the same EPA daily noise dosage limit [27]. To address the dangers of noise pollution, the Center for Disease Control and Prevention (CDC) recommends avoiding prolonged exposure to loud environments to prevent noise-induced hearing loss (NIHL) [18] [28].

Noise pollution also affects the quality of life [29]. Even for people with normal hearing, noise is a barrier to the enjoyment of communicating, socializing and connecting with colleagues, friends and families through intimate conversation. The focus of this study is on indoor noise, specifically in restaurants and bars. Restaurants are not just eating establishments, but social spaces important for gathering and communicating and noise has hindered and negatively affected customers' dining experience [30]. And for those with hearing loss, the difficulty of hearing others in loud venues can lead many to withdraw from social situations, leading to increased isolation [31].

The number of people exposed to high sound levels has tripled since the 1980's [32] due, in part, to the rise of personal music players and louder restaurants and bars. The Speak Easy 2016 survey of 1461 people with and without hearing loss in the United Kingdom (UK) showed that $77 \%$ of respondents reported increasing sound levels in restaurants since 2011 [33].

There are increasing numbers of reports from patrons complaining about the difficulty in conversing with fellow diners due to loud venues. In Zagat's 2016 Annual Survey, when surveyors were asked what irritated them the most about 
dining out, noise was the second highest complaint (25\%) behind poor service (28\%). But in major urban cities of San Francisco, Boston, Portland and New York City, noise was the number one complaint [34]. Zagat also reported that $72 \%$ of New Yorkers actively avoid restaurants that are too loud [35]. In 2015, nearly $80 \%$ of 1232 surveyed people in New Orleans said they "loathe" restaurant noise with noise annoying them the most (27\%) followed by poor service (24\%) [36]. The Speak Easy survey also found that due to venues with loud noise: 1) close to eight out of ten people had left a restaurant, café or bar 2) 79\% had difficulty holding a conversation in such venues, and 3) $91 \%$ stated they would not return to such a venue. Even amongst respondents with no hearing loss, $84 \%$ said they considered lower noise levels important when deciding where to eat [33]. And an organization in the UK called Pipedown that was formed to campaign for freedom from background music has now expanded to the U.S., Canada, Germany, Austria, Switzerland, Holland and South Africa [37].

Noise is clearly an important health and quality-of-life issue. The general public could benefit from information about sound levels of a particular venue for both health and the ability to converse with others. Because many may not know specifically which sound levels comprise a quiet or loud auditory environment, they may be unknowingly endangering their health by patronizing an establishment they believe to be quiet but is actually loud.

The advances of smart-phone technology is providing new ways to capture sound levels with digital sound level meters which could become a valuable tool for improving the public's noise pollution awareness [18]. Ideally, a database would be maintained by a local governmental entity and have frequent and recurring precise sound level measurements of long duration for all venues in a city. And similar to the health grades that are prominently displayed on venue windows, a noise grade would enable patrons to know the general sound level of each venue. Unfortunately, this is impractical due to the high costs of labor, equipment and time. While some people do employ a digital sound level meter on their smart phone to take real-time measurements, such data is not collected, aggregated and widely disseminated for public consumption. What is suggested is a method to systematically quantify the noise levels of a large number of venues employing digital sound level meters and making such information easily accessible to the public.

A few studies have attempted to undertake a systematic quantification of restaurant and bar sound levels in an urban environment, but the number of venues measured were rather small using less than 100 restaurants, ranging from Lebo's study of 27 restaurants in the San Francisco Bay Area in 1994 [38], Yu and Wong's study of 23 restaurants in Hong Kong in 2002 [39], Hannah's study of five restaurants in Wellington, New Zealand in 2004 [40], Ryberg's study of 96 pubs and restaurants in Sweden in 2009 but only those with loud music were analyzed [41], Samagwa's study of seven restaurants in Morogoro, Tanzania in 2009 [42]. To and Chung's study of 12 restaurants in Hong Kong in 2014 [43], 
and Nielsen's study of five restaurants in Denmark in 2016 [13].

Because these studies were based on a small number of restaurants and were not conducted on a continuing basis, the data collected do not accurately represent current sound levels and do not help people determine which venues are quiet or loud. In addition, such information is not easily accessible to the public. Some online websites that rank or describe restaurants and bars such as Yelp do show a venue's sound levels, but when information is included, it is based on subjective interpretation and reporting by venue managers and/or patrons. Such information may not provide accurate data about sound levels.

This exploratory study is based on an effort to capture the sound level data on a large-scale basis in an urban environment (New York City) using the SoundPrint app ("SoundPrint"), a free digital sound level meter available on the iPhone at no cost to users, that measures, aggregates, categorizes and displays the average sound levels of venues into quiet, moderate, loud or very loud categories on an ongoing basis and is easily accessible to the public.

We believe the public lacks sufficient awareness in determining whether a certain auditory environment is quiet or loud. For most people without digital sound level meters, such determination is merely subjective. If most venues are loud, people may erroneously believe that such noise levels are the "norm" and therefore, acceptable and safe. This study aims to compare people's subjective interpretation and reporting of sound levels to actual quantitative measurements.

Another purpose of this study is to determine whether the recent increase in the number of media articles and qualitative surveys indicating that venues are too loud is true and accurate. In answering this, data from SoundPrint was utilized to explore the following: 1) What percentage of venues in Manhattan are quiet or loud? 2) Are there certain types of venues or venues in certain neighborhoods that are generally quieter or louder than others? And 3) Do managers and/or patrons accurately assess and report the sound levels of these venues?

\section{Methodology}

1) Timeline and Geography

The exploratory study was conducted between July 2015 and June 2017 in Manhattan restaurants and bars located between $86^{\text {th }}$ street and the lower edge of Manhattan, otherwise known as the Financial District. Manhattan was chosen for two reasons. First it has a large number of restaurants and bars in a concentrated area making it easier to carry out the large-scale exploratory survey. And second, for its reputation as one of the noisiest cities worldwide. Note that the collection is still ongoing, but for the purposes of this study, June 2017 is the last month of data analyzed for this report.

The major neighborhoods in Manhattan that were assessed include: Upper West Side, Upper East Side, Midtown West, Midtown East, Murray Hill, Koreatown, Chelsea, Flatiron, Gramercy, Union Square, West Village, East Village, 
Tribeca, SoHo, Chinatown, Little Italy, Lower East Side and the Financial District $^{1}$.

2) Venues measured

A total of 3137 restaurants and bars were measured at least once for their sound levels. To qualify for inclusion in the analysis, however, each venue had to be measured a minimum of three times during prime days and hours and many were measured more than three times ${ }^{2,3}$. A total of 2376 restaurants and bars met this minimum requirement for inclusion in this report. Only restaurants that had on-the-premise seating with waiter-based service were included in this analysis; venues that had pick-up-at-the-counter service or no waiters were excluded.

There are several reasons why a venue may not have been measured the minimum three times: a) the venue launched their business after the beginning of the collection stage, thus were not measured at least three times b) the venue was either permanently or temporarily closed (i.e. private event, remodeling, or changed locations), or c) the collector missed the venue when surveying the selected neighborhood or streets.

3) Instrument of measurement

The measurements were conducted with the SoundPrint app, a free digital sound level meter and aggregator available on the iPhone platform. SoundPrint measures $\mathrm{dBA}$ with slow response and automates the sound level calibration across different iPhone hardware devices for a more consistent measurement. The main output is the average dBA (an arithmetic average) as this represents sufficient information for individuals to measure, understand and employ in making decisions about whether to patronize a venue.

To illustrate, the average $\mathrm{dBA}$ output is the result of collecting the average $\mathrm{dBA}$ of each individual measurement, and averaging across those measurements. To illustrate, if one venue had three separate average measurements of $72 \mathrm{dBA}$, $74 \mathrm{dBA}$ and $78 \mathrm{dBA}$, then the venue's $\mathrm{dBA}$ used for this analysis would be 75 dBA.

The SoundPrint app's sound level measurement accuracy was tested in two separate ways. First the app's sound measurement capabilities were tested side by side with a Type-1 sound level meter at various levels of pink noise. Agreement was within $\pm 0-1.2 \mathrm{~dB}$ at all levels ${ }^{4}$. And second, it was compared to the

${ }^{1}$ The West Village is comprised of the West Village and Greenwich Village. Flatiron/Gramercy also includes Union Square and SoHo includes Nolita.

${ }^{2}$ The highest number of times a venue was measured was 18 .

${ }^{3}$ The breakdown of the number of venues measured " $x$ " times is as follows: 1 measurement: 366 venues; 2 measurements: 395 venues; 3 measurements: 861 venues; 4 measurements: 718 venues; 5 measurements: 381 venues; 6 measurements: 233 venues; 7 measurements: 107 venues; 8 measurements: 48 venues; 9 measurements: 18 venues; 10 measurements: 4 venues; 11 measurements: 2 venues; 12 measurements: 0 venues; 13 measurements: 1 venue; 14 measurements, 0 venues; 15 measurements, 1 venue; 16 measurements, 1 venue; 17 measurements, 0 venues; and 18 measurements, 1 venue.

${ }^{4}$ The tests were conducted using four iPhone 6 models and an iPhone 7 by Lily M. Wang and Kieren Smith (Durham School of Architectural Engineering and Construction, University of Nebraska-Lincoln). 
Faber Sound Meter 4 iPhone app, referred to as the SoundMeter app and available on the Apple store, which was found by Chuck Kardous at NIOSH to be the most accurate within $0.2 \%$ of an OSHA-certified sound level meter [44]. Results show that across seven different general static sound level decibel ranges, SoundPrint was within \pm 0 - 1 dBA of the SoundMeter app ${ }^{5}$.

SoundPrint allows the user to see the average sound level of an individual venue that has been measured and submitted to the database. Users can see the sound levels of individual venues in the SoundPrint app in three ways: a) in a list sorted by sound levels (how quiet or loud they are) b) on a visual map showing the sound levels of venues in a certain geographical area (i.e. East Village), or c) by searching for a specific venue by name in the search bar. Note that the sound levels of individual venues available in SoundPrint are not shown or analyzed in this study, only aggregated data is.

4) How measurements were taken and submitted

To take a measurement, the 24 collectors, recruited through friends and posting sites, were instructed to measure from a central spot in the venue. If this was deemed not to be an effective location by the collector, then the measurement took place closer to the source of the ambient sound. The collector was instructed to ensure that there was at least three feet of space extending outward in all radial and azimuthal angles from the microphone during the measurement. Note that regular users of the SoundPrint app also crowdsourced their sound level measurements to the database.

Each measurement is run for a minimum duration of 15 seconds and calculates the average sound level over the length of the measurement. Note that while the minimum duration is 15 seconds, the collector was instructed to measure for the amount of time necessary to sufficiently reflect the actual sound level. Thus, many of the measurements exceeded 15 seconds. When the collector ended the measurement, he or she then tagged the measurement to the venue name and submitted it to the SoundPrint database. The database then produced an arithmetic average sound level for each venue based on all the submitted measurements tagged to the venue.

5) Measurement collections

The measurements were collected during prime-time days and hours which included: Wednesdays from 7:00PM-9:00PM, Thursdays from 7:00PM-9:30PM, Fridays from 7:00PM-10:00PM and Saturdays from 7:00PM-10:00PM.

6) Sound level categories

As shown in Table 1, the data is segmented into four sound level categories: a) Quiet b) Moderate c) Loud d) Very Loud.

All four categories have sound level thresholds that are guided by hearing health safety standards, but the Moderate and Loud categories are also guided by

${ }^{5}$ Note that SoundPrint measures $\mathrm{dBA}$ in whole integers whereas SoundMeter measures to the $1 / 10^{\text {th }}$ decibel. To illustrate, in a quiet room where SoundMeter measured at $43.8 \mathrm{dBA}$, it was rounded to $44 \mathrm{dBA}$. SoundPrint measured at $45 \mathrm{dBA}$. We do not know if SoundPrint's dBA to the $1 / 10^{\text {th }}$ level was $44.5,44.6,44.7,44.8,44.9,45.0,45.1,45.2,45.3$, or 45.4 . 
the threshold sound level where the ability to hear and converse with others becomes either easier or difficult. Note that the Discussion section discusses and compares SoundPrint's four categories of Quiet, Moderate, Loud, and Very Loud to Yelp's four noise level categories of Quiet, Average, Loud and Very Loud.

i) Less than $70 \mathrm{dBA}$ (Quiet)

In 1972, The National Institute of Occupational Safety and Health (NIOSH) stated that average, not peak, sound levels over a time-weighted eight-hour period above $85 \mathrm{dBA}$ is the threshold by which employers should enact hearing conservation programs to protect against the danger of noise induced hearing loss. This was a standard specifically set for employers and employees in occupational settings for the standard eight-hour work day. Yet guidelines were also needed for the general public to account for their noise exposure for the full 24-hours in a day. Two years later, the Environmental Protection Agency (EPA) calculated a safe noise exposure level for the general public on a daily basis to be $70 \mathrm{dBA}$ [45]. This means that, on average, during a typical 24-hour day, one's noise exposure should be $70 \mathrm{dBA}$ or lower to protect against noise-induced hearing loss according to the EPA. This threshold has been supported by the World Health Organization (WHO) that has recommended people avoid sound level exposures above $70 \mathrm{dBA}$ [46]. Hence the Quiet category reflects an average $\mathrm{dBA}$ of 70 or lower.

ii) $81 \mathrm{dBA}$ or louder (Very Loud)

Notwithstanding the above, NIOSH's $85 \mathrm{dBA}$ standard is not meant to protect all workers as NIOSH acknowledged that $8 \%$ of workers could still develop material hearing loss under their guidelines. Also, the $85 \mathrm{dBA}$ threshold level assumes that the employee has no further noise exposure during the remaining 16 non-working hours each day and accounted for only 40 occupational-work years for noise exposure rather than the 80-year life expectancy today [47] [48]. In 2003, the European Parliament established new, and more stringent, standards for acceptable occupational noise exposure levels as it lowered the threshold by which companies must make hearing protection available from $85 \mathrm{dBA}$ to 80 dBA [49]. Thus, SoundPrint employs the more conservative $80 \mathrm{dBA}$ as the threshold for a venue being Very Loud and potentially dangerous to one's hearing health.

iii) Between 71 and $75 \mathrm{dBA}$ (Moderate) and Between 76 and $80 \mathrm{dBA}$ (Loud)

The EPA has shown that normal hearing people have difficulty following a conversation above $75 \mathrm{dBA}$ [45]. This is supported by Lebo et al.'s description of restaurants with noise levels of $75+\mathrm{dBA}$ as those that made conversation difficult for patrons with normal hearing and very difficult for those with hearing loss [38]. Loud noise could alternatively be described as an auditory environment where people must raise their voice to be heard by someone sitting within three feet of them. And in 1990, The National Institute of Health Consensus Development Conference on Noise and Hearing Loss stated that $75 \mathrm{dBA}$ is the 
threshold by which, if the sound level is lower, is unlikely to cause permanent hearing loss [50]. This implies that as the sound level increases above $75 \mathrm{dBA}$, the likelihood of incurring permanent hearing loss increases. Hence SoundPrint sets $75 \mathrm{dBA}$ as the threshold between the Moderate and Loud categories.

An alternative interpretation for the Loud category is that it could represent an auditory environment that is more likely to be conducive to a fun, exciting atmosphere with lively music, lots of people in attendance, and loud conversation or shouting.

In summary, the four sound level categories are: i) $70 \mathrm{dBA}$ or lower (Quiet) ii) Between 71 - $75 \mathrm{dBA}$ (Moderate) iii) Between 76 and $80 \mathrm{dBA}$ (Loud), and iv) 81 dBA or higher (Very Loud).

The presentation of the data in this study is represented as Low, Moderate and High with the High category separated into two categories, Loud and Very Loud. The High category reflects the sound level threshold above $76 \mathrm{dBA}$ and, as the $\mathrm{dBA}$ level increases, the likelihood of incurring noise-induced hearing loss increases and the ability to converse with others becomes more difficult.

7) Restaurant classifications

The analysis also categorizes restaurants by various classifications that include user ratings, cost, ambience and type of cuisine. This information was gleamed from each venues' business listing on the Yelp website ("Yelp") which displays the aforementioned variables.

8) Analysis of managers and/or patrons' assessment and reporting of venue's sound levels

The study also attempts to gauge the accuracy of the manager and patron's reporting of a venue's sound level. When filling out their business listing survey on Yelp, managers can choose one of four sound level categories: Quiet, Average, Loud or Very Loud. Patrons, or a Yelp reviewer, can subsequently fill out a similar survey when writing a Yelp review. Note that Yelp does not assist the user in providing the associated numerical $\mathrm{dBA}$ range associated with each sound level category. Instead it relies on the subjective assessment and reporting of the manager and/or patron.

The data was collected and analyzed as follows: First, the venue's sound level categorization was quantitatively measured and categorized by SoundPrint as either Quiet, Moderate, Loud or Very Loud. Then this categorization was compared to Yelp's sound level categories.

Table 1. Summary of sound level categories.

\begin{tabular}{cccc}
\hline Category & dBA & Conversation & Hearing Health \\
\hline Quiet & 70 or below & Great & Safe \\
Moderate & $71-75$ & Feasible & Safe \\
High & 76 or higher & & \\
Loud & $76-80$ & Difficult & Likely safe \\
Very Loud & 81 or higher & Very difficult & Likely unsafe \\
\hline
\end{tabular}


A venue manager's reporting was marked as "Matched" when the venue's Yelp business listing reported the same sound level category as SoundPrint's categorization. For example, if SoundPrint measured “John Smith Restaurant" as having an average sound level of $69 \mathrm{dBA}$ over three submitted measurements, it would be categorized as Quiet. And if “John Smith Restaurant's” Yelp business page reported the sound level as Quiet, then it was marked as "Matched." If the venue had listed itself as Average, Loud, or Very Loud, then it was marked as "Mismatched." Similarly, if SoundPrint categorized a venue as either Loud or Very Loud and the venue's Yelp business page reported the sound level as either Loud or Very Loud, then it was marked as "Matched." But if it was reported as Quiet or Average, then it was marked as "Mismatched."

9) Limitations

There are several limitations to this exploratory study. First, the SoundPrint digital sound level meter app was used rather than a highly advanced sound level measuring instrument. Although SoundPrint provides a reasonable approximate measurement of the sound level, it is not sufficiently accurate for legally-based measurements. Second, only one variable, the average dBA was measured and aggregated as other variables that could provide additional insight such as minimum or maximum sound levels, occupational density and/or reverberation or other room characteristics such as clarity were not measured. Third, the length of the recordings is typically shorter than the measurements conducted in prior restaurant noise studies. This was due to the restrictive timeframe for primetime days and hours, the large number of venues needed for measurement at least three times and the limited amount of human resources to complete the measurements.

Fourth, there is no uniform recording length for each submission as the length of the recording varies since it the user's decision as to when to stop each recording, despite there being a minimum 15 seconds. The vast majority of submissions were under one minute. Fifth, due to the nature of the app being a crowdsourcing app and despite giving instructions to collectors and users, there is not a verifiable way to ensure they followed precise instructions (i.e. record from the center of the room, ensure at least three feet of space in a 360 degree angle) during their measurements. Additionally, the resulting average sound levels for a particular venue could differ from the sound levels during other times on the same day. It is possible that a collector took a measurement of a venue that was quieter or louder at a specific time and then an hour later the venue produces a louder or quieter sound level that may be more typical for the venue.

\section{Data}

In general, Tables 2-4 show the percentage breakdown of venues by sound level categories. Tables 5-8 show the average sound level of restaurants by various segments such as User Ratings, Cost, Ambience, and Cuisine Type. Table 9 represents the percentage breakdown of correct assessments and reporting by 
Table 2. Sound levels by categories for all restaurants.

\begin{tabular}{cccccccc}
\hline & Total & Below 71 & $71-75$ & $76+$ & $76-80$ & $81+$ & \multirow{2}{*}{ Avg dBA } \\
\cline { 3 - 6 } & & Low & Mod & High & Loud & Very Loud & \\
\hline Chinatown & 55 & $29 \%$ & $53 \%$ & $18 \%$ & $16 \%$ & $2 \%$ & 72.4 \\
Upper East Side & 165 & $19 \%$ & $33 \%$ & $48 \%$ & $35 \%$ & $13 \%$ & 74.9 \\
Upper West Side & 92 & $17 \%$ & $34 \%$ & $49 \%$ & $38 \%$ & $11 \%$ & 75.1 \\
Midtown East & 163 & $16 \%$ & $35 \%$ & $49 \%$ & $29 \%$ & $20 \%$ & 75.6 \\
Midtown West & 277 & $13 \%$ & $31 \%$ & $56 \%$ & $35 \%$ & $21 \%$ & 76.2 \\
Little Italy & 40 & $8 \%$ & $45 \%$ & $48 \%$ & $35 \%$ & $13 \%$ & 76.4 \\
Tribeca & 57 & $9 \%$ & $30 \%$ & $61 \%$ & $40 \%$ & $21 \%$ & 76.7 \\
Koreatown & 24 & $4 \%$ & $25 \%$ & $71 \%$ & $63 \%$ & $8 \%$ & 77.3 \\
Chelsea & 76 & $9 \%$ & $20 \%$ & $71 \%$ & $41 \%$ & $30 \%$ & 77.5 \\
${ }^{1}$ Murray Hill & 81 & $10 \%$ & $23 \%$ & $67 \%$ & $33 \%$ & $33 \%$ & 77.8 \\
Financial District & 33 & $6 \%$ & $27 \%$ & $67 \%$ & $33 \%$ & $33 \%$ & 77.9 \\
${ }^{2}$ West Village & 261 & $5 \%$ & $23 \%$ & $72 \%$ & $42 \%$ & $30 \%$ & 78.1 \\
East Village & 225 & $4 \%$ & $18 \%$ & $78 \%$ & $46 \%$ & $32 \%$ & 78.3 \\
${ }^{3}$ SoHo & 41 & $2 \%$ & $15 \%$ & $83 \%$ & $44 \%$ & $39 \%$ & 78.6 \\
${ }^{4}$ Flatiron & 123 & $2 \%$ & $19 \%$ & $79 \%$ & $46 \%$ & $33 \%$ & 78.7 \\
Lower East Side & 75 & $0 \%$ & $11 \%$ & $89 \%$ & $41 \%$ & $48 \%$ & 80.3 \\
Total & $\mathbf{1 7 8 8}$ & $\mathbf{1 0} \%$ & $\mathbf{2 7 \%}$ & $\mathbf{6 3 \%}$ & $\mathbf{3 8 \%}$ & $\mathbf{2 5 \%}$ & $\mathbf{7 7 . 0}$ \\
\hline
\end{tabular}

${ }^{1}$ Includes Murray Hill, Kips Bay; ${ }^{2}$ Includes West Village, Greenwich Village; ${ }^{3}$ Includes SoHo, Nolita; ${ }^{4}$ Includes Flatiron, Gramercy, Union Square.

Table 3. Sound levels by categories for Mainstream restaurants (excluding Asian and Indian restaurants).

\begin{tabular}{cccccccc}
\hline & Total & Below 71 & $71-75$ & $76+$ & $76-80$ & $81+$ & \multirow{2}{*}{ Avg dBA } \\
\cline { 3 - 6 } Chinatown & 4 & $25 \%$ & $50 \%$ & $25 \%$ & $25 \%$ & $0 \%$ & 73.0 \\
Upper West Side & 55 & $11 \%$ & $33 \%$ & $56 \%$ & $44 \%$ & $13 \%$ & 75.8 \\
Koreatown & 5 & $0 \%$ & $60 \%$ & $40 \%$ & $40 \%$ & $0 \%$ & 76.4 \\
Upper East Side & 119 & $8 \%$ & $32 \%$ & $60 \%$ & $41 \%$ & $18 \%$ & 76.5 \\
Midtown West & 212 & $11 \%$ & $27 \%$ & $62 \%$ & $36 \%$ & $25 \%$ & 76.8 \\
Midtown East & 114 & $11 \%$ & $33 \%$ & $55 \%$ & $29 \%$ & $26 \%$ & 76.9 \\
Little Italy & 34 & $0 \%$ & $47 \%$ & $53 \%$ & $38 \%$ & $15 \%$ & 77.3 \\
Tribeca & 41 & $5 \%$ & $24 \%$ & $71 \%$ & $44 \%$ & $27 \%$ & 77.5 \\
Financial District & 30 & $7 \%$ & $23 \%$ & $70 \%$ & $37 \%$ & $33 \%$ & 78.0 \\
Chelsea & 58 & $5 \%$ & $17 \%$ & $78 \%$ & $47 \%$ & $31 \%$ & 78.2 \\
Murray Hill & 63 & $8 \%$ & $17 \%$ & $75 \%$ & $35 \%$ & $40 \%$ & 78.8 \\
${ }^{1}$ West Village & 214 & $1 \%$ & $20 \%$ & $79 \%$ & $43 \%$ & $36 \%$ & 78.9 \\
2Soho & 35 & $0 \%$ & $11 \%$ & $89 \%$ & $49 \%$ & $40 \%$ & 79.0 \\
${ }^{3}$ Flatiron/Gramercy & 102 & $1 \%$ & $19 \%$ & $80 \%$ & $45 \%$ & $35 \%$ & 79.0 \\
${ }^{4}$ East Village & 152 & $3 \%$ & $13 \%$ & $84 \%$ & $45 \%$ & $39 \%$ & 79.1 \\
Lower East Side & 56 & $0 \%$ & $9 \%$ & $91 \%$ & $38 \%$ & $54 \%$ & 81.0 \\
Total & 1294 & $6 \%$ & $23 \%$ & $71 \%$ & $40 \%$ & $31 \%$ & 78.0 \\
\hline
\end{tabular}

${ }^{1}$ Includes West Village, Greenwich Village; ${ }^{2}$ Includes Murray Hill, Kips Bay; ${ }^{3}$ Includes Flatiron, Gramercy, Union Square; ${ }^{4}$ Includes SoHo, Nolita. 
Table 4. Sound levels by categories for all bars.

\begin{tabular}{cccccccc}
\hline & Total & Below 71 & $71-75$ & $76+$ & $76-80$ & $81+$ & \multirow{2}{*}{ Avg dBA } \\
\cline { 3 - 6 } & & Low & Mod & High & Loud & Very Loud & \\
\hline Upper East Side & 42 & $2 \%$ & $19 \%$ & $79 \%$ & $40 \%$ & $38 \%$ & 78.9 \\
Upper West Side & 23 & $4 \%$ & $4 \%$ & $91 \%$ & $39 \%$ & $52 \%$ & 79.9 \\
Midtown West & 86 & $1 \%$ & $13 \%$ & $86 \%$ & $38 \%$ & $48 \%$ & 80.1 \\
Financial District & 22 & $5 \%$ & $9 \%$ & $86 \%$ & $27 \%$ & $59 \%$ & 80.1 \\
Chelsea & 31 & $0 \%$ & $16 \%$ & $84 \%$ & $29 \%$ & $55 \%$ & 81.1 \\
Tribeca & 22 & $0 \%$ & $0 \%$ & $100 \%$ & $36 \%$ & $64 \%$ & 81.6 \\
${ }^{1}$ West Village & 70 & $1 \%$ & $6 \%$ & $93 \%$ & $40 \%$ & $53 \%$ & 81.7 \\
${ }^{2}$ Soho & 16 & $0 \%$ & $6 \%$ & $94 \%$ & $31 \%$ & $63 \%$ & 81.8 \\
Midtown East & 33 & $6 \%$ & $6 \%$ & $88 \%$ & $24 \%$ & $64 \%$ & 81.8 \\
${ }^{3}$ Flatiron-Gramercy & 37 & $0 \%$ & $5 \%$ & $95 \%$ & $24 \%$ & $70 \%$ & 82.0 \\
East Village & 126 & $2 \%$ & $5 \%$ & $94 \%$ & $25 \%$ & $69 \%$ & 82.0 \\
Lower East Side & 44 & $0 \%$ & $5 \%$ & $95 \%$ & $25 \%$ & $70 \%$ & 82.2 \\
${ }^{4}$ Murray Hill & 28 & $0 \%$ & $11 \%$ & $89 \%$ & $18 \%$ & $71 \%$ & 82.3 \\
Little Italy & 4 & $0 \%$ & $0 \%$ & $100 \%$ & $25 \%$ & $75 \%$ & 82.5 \\
Koreatown & 2 & $0 \%$ & $0 \%$ & $100 \%$ & $0 \%$ & $100 \%$ & 84.5 \\
Chinatown & 2 & $0 \%$ & $0 \%$ & $100 \%$ & $0 \%$ & $100 \%$ & 85.0 \\
Total & $\mathbf{5 8 8}$ & $\mathbf{2 \%}$ & $\mathbf{8} \%$ & $\mathbf{9 0 \%}$ & $31 \%$ & $\mathbf{6 0} \%$ & $\mathbf{8 1 . 3}$ \\
\hline
\end{tabular}

${ }^{1}$ Includes West Village, Greenwich Village; ${ }^{2}$ Includes SoHo and Nolita; ${ }^{3}$ Includes Flatiron, Gramercy, Union Square; ${ }^{4}$ Includes Murray Hill, Kips Bay.

Table 5. Average sound levels by user ratings.

\begin{tabular}{ccc}
\hline & Total & Avg dBA \\
\hline Low rated & 236 & 76.1 \\
Average rated & 734 & 76.7 \\
High rated & 818 & 77.5 \\
\hline
\end{tabular}

Table 6. Average sound levels by cost.

\begin{tabular}{ccc}
\hline & Total & Avg dBA \\
\hline Cheap \$ & 52 & 75.2 \\
Average \$\$ & 1216 & 77.2 \\
Moderate \$\$ & 428 & 77.0 \\
Expensive \$\$\$ $\$$ & 91 & 75.9 \\
\hline
\end{tabular}

Table 7. Average sound levels by ambience.

\begin{tabular}{ccc}
\hline & Total & Avg dBA \\
\hline Casual & 1008 & 77.0 \\
Trendy, Classy or Upscale & 364 & 77.8 \\
Intimate & 192 & 75.8 \\
\hline
\end{tabular}


Table 8. Average sound levels by cuisine.

\begin{tabular}{ccc}
\hline & Total & Avg dBA \\
\hline Indian & 54 & 72.6 \\
Chinese & 107 & 72.9 \\
Vietnamese & 18 & 73.1 \\
Japanese & 186 & 74.4 \\
Middle Eastern & 24 & 75.0 \\
Thai & 50 & 75.2 \\
French & 100 & 75.7 \\
Italian & 329 & 75.9 \\
1Mediterrarean & 73 & 77.5 \\
Korean & 28 & 78.0 \\
German & 12 & 78.5 \\
Spanish & 40 & 79.0 \\
U.S. & 533 & 79.0 \\
${ }^{2}$ Latin & 51 & 79.0 \\
Mexican & 100 & 80.4 \\
\hline
\end{tabular}

${ }^{1}$ Includes Greek, Turkish and Mediterrean. ${ }^{2}$ Central and South American cuisines, excludes Mexican.

Table 9. Matching of self-reporting by venues/patrons-bars and restaurants.

\begin{tabular}{ccccc}
\hline & \multicolumn{2}{c}{ Quiet } & \multicolumn{2}{c}{ Loud and Very Loud } \\
\cline { 2 - 5 } & Unmatched & Matched & Unmatched & Matched \\
\hline Total & 132 & 46 & 1521 & 114 \\
Total - \% & $74 \%$ & $26 \%$ & $93 \%$ & $7 \%$ \\
\hline
\end{tabular}

managers and/or patrons, as gleaned from the venue's Yelp business listing.

In detail, Table 2 and Table 3 show the percentage breakdown by sound level categories of "All Restaurants" and "Mainstream Restaurants." The tables also show the breakdown by neighborhood to enable comparisons between different areas in Manhattan. Table 2 represents all the restaurant venues in the study. The study analyzed restaurants that had waiter-based service and on-the-premise dining for patrons. However, some of these restaurants also offered takeout and delivery options and generated much of their revenue from one of these two options. It became evident to collectors that these restaurants were often either relatively empty or had minimal patrons dining on the premises, which meant the sound level often measured as Quiet.

These venues do not represent the type of restaurant the study targets, which are those that generate their business primarily from customers dining on-the-premises. Consequently, a second category titled "Mainstream Restaurants", was formed as an alternative, but not exact, approach to analyze restaurants that were mainly on-the-premise dining establishments. The restaurants 
that earned most of their business via takeout and delivery, and also had on-the-premise seating with mostly empty tables, were predominantly Asian and Indian cuisine-based restaurants. Thus, the Mainstream Restaurant table excludes all Asian and Indian restaurants at the expense of excluding those Asian and Indian restaurants that generate most of their revenue via on-the-premise dining.

\section{Results}

1) Restaurants

For restaurants, as shown in Table 2, including those that have a significant delivery and take-out presence, $10 \%$ of the venues are Quiet, 27\% are Moderate, and $63 \%$ are High with $38 \%$ being Loud and $25 \%$ Very Loud ${ }^{6}$. The average sound level for all restaurants was $77 \mathrm{dBA}$.

2) Mainstream Restaurants (On-the-Premise Dining)

For Mainstream Restaurants, as shown in Table 3,6\% are Quiet, 23\% are Moderate, $71 \%$ are High with $40 \%$ being Loud and $31 \%$ Very Loud. The average sound level for all mainstream restaurants was $78 \mathrm{dBA}$.

Many of the neighborhoods below $34^{\text {th }}$ Street (excluding the Financial District, Little Italy and Chinatown) tend to be louder than those above $34^{\text {th }}$ Street. On the Lower East Side of Manhattan, 0\% of the restaurants measured are Quiet, 9\% are Moderate and $91 \%$ are High with 38\% being Loud and 54\% being Very Loud. The Lower East Side, Tribeca, SoHo, Chelsea, East Village, West Village, Flatiron and Murray Hill all have $+70 \%$ of their venues in the High category. Not surprisingly, these neighborhoods also have the highest average sound levels for restaurants. In contrast, neighborhoods above $34^{\text {th }}$ Street, except Murray Hill, such as the Upper West Side, Upper East Side, Midtown East and Midtown West tend to have a lower percentage of venues in the High category and also lower average sound levels.

3) Bars

For bars, as shown in Table 4, 2\% are Quiet, $8 \%$ are Moderate and $90 \%$ are High with $31 \%$ being Loud and $60 \%$ Very Loud. The average sound level for all bars was $81 \mathrm{dBA}$. Segmenting the data into neighborhoods shows a similar pattern consistent with the restaurant data as the same neighborhoods tend to have higher sound levels than their uptown brethren above $34^{\text {th }}$ Street.

4) Restaurants by Cost, User Ratings, Ambience and Cuisine

For restaurants segmented by User Ratings, as shown in Table 5, a positive correlation was found between sound levels and User Ratings, and while statistically significant at the $\mathrm{p}<0.01$ level, the relationship is not strong $(\mathrm{R}=0.093)$. For restaurants segmented by Cost, as shown in Table 6, there was no statistically significant relationship found between the price of a venue and the average sound level experienced. For restaurants segmented by Ambience, as shown in Table 7, the different ambiences are associated with differences in sound levels,

${ }^{6}$ Throughout this analysis, percentages may not add to $100 \%$ due to rounding. 
confirmed by a significant ( $\mathrm{p}=0.000$ ) one-way ANOVA test and Games-Howell post-hoc values (all significant at the $\mathrm{p}<0.05$ level). Trendy, Classy and Upscale (TCU) restaurants are associated with the highest levels, Intimate with the lowest and Casual between the two.

For restaurants segmented by Cuisine, as shown in Table 8, the different cuisine types were found to have statistically significant differences in measured sound level. An ANOVA test conducted with the different cuisine groups was found to be highly significant ( $p=0.000)$. Indian (73 dBA), Chinese (73 dBA), Vietnamese (73 $\mathrm{dBA})$ and Japanese $(74 \mathrm{dBA})$ restaurants comprise the relatively quieter restaurants compared to the Mexican (80 dBA), Latin (79 dBA), American (79 dBA), Spanish (79 dBA), Korean (78 dBA) and Mediterranean (77 dBA) restaurants.

5) Manager's assessment and reporting of sound levels

For the Quiet venues, as shown in Table 9, 26\% of the Yelp venue listings matched with SoundPrint's data as being Quiet and 74\% mismatched as a category other than Quiet. For the Loud or Very Loud venues, 7\% matched with SoundPrint's data as being Loud or Very Loud and $93 \%$ mismatched with SoundPrint's data.

\section{Discussion}

1) A significant majority of restaurants are likely too loud for conversation and connecting with others

As Tables 2-4 suggest, the number of venues that are Loud or Very Loud is significantly high. For Mainstream Restaurants, 71\% produce average sound levels above the threshold that is likely to be too difficult to have a conversation without the need to raise one's voice. This is supported by the average sound level being $78 \mathrm{dBA}$ which means that if a patron were to patronize a randomly selected restaurant during peak days and hours in Manhattan, it would likely be Loud. Also, a significant majority of bars (90\%) are also Loud or Very Loud.

This data lends credence to the anecdotal comments, recent surveys and increasing number of media articles that suggest that restaurants and bars are most often too loud for conversation and socializing.

2) A significant number of restaurants and bars are dangerous to people's hearing health

Approximately $31 \%$ of Mainstream restaurants and $60 \%$ of all bars have sound levels during peak days and hours that are potentially dangerous to the hearing health of their patrons, and even more importantly, to their employees (i.e. waiters, hostesses, bartenders, chefs and managers) who are often subject to a longer duration of exposure to occupational noise. The average sound level of a Manhattan bar is $81 \mathrm{dBA}$ which means that if a person were to patronize a randomly selected bar during peak days and hours in Manhattan, it would likely be Very Loud.

A venue employee's hearing health could be in serious jeopardy since 
noise-induced hearing loss often does not appear until years later, which by then is too late [51] [52]. And for patrons, their hearing health also depends greatly on the amount and degree of noise exposure they experience during the rest of their 24-hour day, that is whether their average daily noise exposure falls below the $70 \mathrm{dBA}$ threshold recommended by the EPA.

3) Some neighborhoods are louder than others

Manhattan neighborhoods are well-known for their diversity and that is also reflected in the data. Neighborhoods known to skew younger in age and those that have a more vibrant nightlife also tend to have a higher percentage of restaurants that are Loud or Very Loud including the Lower East Side, SoHo, East Village, West Village, Chelsea, Flatiron and Murray Hill-all have more than $75 \%$ of their venues as Loud or Very Loud.

That these neighborhoods are comparatively louder than other neighborhoods is not a surprise. The Upper West Side and Upper East Side are known to be more family-oriented, residential, skew older in age and have less of a vibrant night life. Midtown West and Midtown East are neighborhoods with a mix of residential units and business offices with less people frequenting restaurants during the evening hours compared to the daytime. There are still a good number of venues that are well attended in the evenings, just less so compared to their downtown brethren.

This data could assist people by informing them of the neighborhoods that have quieter or noisier restaurants and bars based on their sound level preference and could be a deciding factor in choosing which neighborhood to live in. The data could also assist local governance in Manhattan, notably the community boards that represent certain districts and recommend various policies to government agencies. These community boards now have access to data that, should they deem it an important health issue, could help them undertake and direct noise pollution awareness efforts.

4) User Ratings, Cost and Ambience trends

Table 5 suggests that High user-rated restaurants are louder than Average user-rated restaurants which are higher than Low user-rated restaurants. This is not surprising as one may expect that more people attend higher rated restaurants but without accounting for occupational density, this cannot be truly tested. The statistical correlation between the two factors can only account for approximately $9 \%$ of the variation in the sound level, so the relationship is not strong.

Table 6 suggests that Average priced restaurants tend to be louder than Moderate, Expensive and Cheap restaurants. We hypothesize that more people patronize an Average priced restaurant compared to a Moderate or Expensive one and hence such restaurants are more crowded. However, when a statistical correlation was run, there was no significant relationship found.

Table 7 suggests that Intimate restaurants are quieter than Casual or Trendy, Classy or Upscale ones. The collectors noted that Intimate restaurants tended to 
have lower table density, more carpeting and tablecloths and lower or less background music. However, each individual restaurant was not quantifiably surveyed based on these features and hence this trend cannot be deemed to be a reliable predictor of sound levels. The differences between the means of the values in the three categories were found to be statistically different from one another.

5) Restaurants serving certain cuisines types may be louder or quieter than others

Table 8 suggests that restaurants may be quieter or louder based on their Cuisine Type. This is not surprising since the collectors observed that Indian, Chinese and Japanese restaurants tended to have less background music, more carpeting and tablecloths to absorb sound and that the patrons tended not to talk as loud compared to patrons of venues with different cuisines. Whether the latter was due to less background music that would otherwise require patrons to raise their voices, otherwise known as the Lombard effect, or due to the type of people who patronize these venues who tend to be quieter cannot be determined without resorting to cultural stereotypes (i.e. Latin, Greek, American and Korean venues tend to have patrons who are louder).

Thus, if a patron desires a quieter restaurant, their chances of finding one is likely to be greater at either Indian or Chinese venues.

6) Accuracy of sound level reporting by managers and/or patrons

Table 9 suggests that user-based subjective reporting of sound levels by managers and/or reviewers on Yelp does not match the objective measurements of Sound Print's data: a) 74\% of Sound Print's Quiet venues are reportedly mismatched as being Average, Loud, or Very Loud on Yelp, and b) 93\% of Sound Print's Loud or Very Loud venues are reportedly mismatched as being either Quiet or Average.

This suggests that the general public lacks sufficient awareness about what constitutes a quiet or loud auditory environment. Consequently, should people be relying on such subjective interpretation, they may be unknowingly placing themselves in Loud or Very Loud auditory environments they believe to be Quiet or Moderate which could be dangerous to their hearing health.

7) Sound level trends over time-to be determined

There appears to be an increase in the sound levels of restaurants over the past 10 years as noted by the number of articles in the media, qualitative surveys and anecdotal comments about the so-called "increasing din" of restaurants. Thus, it would be beneficial to quantifiably gauge whether restaurants are actually getting louder over time. Because this is the first exploratory study, we cannot determine trends or make comparisons at this time. However, we aim to collect additional data and conduct comparative analyses to this study's data on an annual or biennial basis in the future.

\section{Conclusion and Recommendations}

In this exploratory study, the data suggests that the increasing number of media 
articles and anecdotal comments from qualitative noise surveys about sound levels being too loud are correct. In New York City, a significant number of restaurants and bars in New York City have average sound levels that 1) approach levels that are too difficult for patrons to have a conversation without the need to raise their voice and 2) approach levels that are known to be dangerous to hearing health. The average $\mathrm{dBA}$ for all restaurants included in this study is $77 \mathrm{dBA}$, for mainstream restaurants $78 \mathrm{dBA}$, and for all bars is $81 \mathrm{dBA}$. A person randomly walking into a restaurant or a bar in New York City during prime days and hours is more likely than not to encounter a Loud or Very Loud auditory environment.

Furthermore, the sound levels of venues in New York City tend to be correlated with certain neighborhoods, possibly as a reflection of the venues in that neighborhood that attract a certain demographic. The sound levels also tend to be correlated with types of ethnic cuisines, possibly reflecting certain cultural preferences for the type of dining experience that appeal to the venue owners and patrons. Further investigation is needed to support these findings, notably by conducting measurements using precision sound level meters, measuring more variables including minimum and maximum sound levels, occupational density and reverberation, as well as measuring a significantly larger number of restaurants and bars compared to the number measured in the smaller scale noise surveys. The relationship between sound levels and other variables such as a venue's user rating, cost or ambience also need to be explored on a large scale.

The data also suggests that venue managers and patrons are not very accurate in assessing and reporting the actual sound levels of venues-93\% of venues that are either Loud or Very Loud by SoundPrint's objective measurements were reportedly mismatched, on a qualitative basis, as either Quiet or Average. This means that people may be patronizing or working in venues that are Loud or Very Loud that they mistakenly believe to be Quiet or Moderate.

Because traditional scientific sound level measurement practices are time and labor-intensive, it has made large-scale collection of sound level data on individual venues difficult. This results in a public today that has lacked accessibility to and knowledge about the sound levels of venues in their neighborhood. Such access is needed to help people determine whether a particular venue is likely to be quiet or loud, whether for social purposes (to be able to have a conversation) or to protect their hearing health. But with the advent of smartphone technology, the public now has the available tools, via digital sound level meters, to collect, crowdsource and create large sets of evidence-based sound level data for researchers, public health agencies and local governments to begin monitoring the effect of noise on hearing health and more effectively raise noise pollution awareness.

\section{Acknowledgements}

Thank you to Arline Bronzaft, Lily M. Wang and Daniel Fink for their support, 
encouragement and helpful comments on earlier versions of the paper. Special thanks to Kieren Smith for her work on the validation measurements and statistical analyses.

\section{References}

[1] Reiley, L. (2007) All that Racket a Lose-Lose Situation for Restaurants. Tampa Bay Times, 13 September 2007.

[2] Sietsema, T. (2008) No Appetite for Noise. Washington Post, 6 April 2008. http://www.washingtonpost.com/wp-dyn/content/article/2008/04/01/AR200804010 2210_pf.html

[3] Mclaughlin, K. (2010) Pass the Salt....and a Megaphone. The Wall Street Journal. https://www.wsj.com/articles/SB10001424052748704022804575041060813407740

[4] Bauer, M. (2011) Five of the Noisiest Restaurants in the Bay Area. SFGate, 9 March 2011.

http://insidescoopsf.sfgate.com/blog/2011/03/09/five-of-the-noisiest-restaurants-inthe-bay-area/

[5] Hsu, T. (2012) Noisy Restaurants: Taking the Din Out of Dinner. Los Angeles Times, 8 Jun 2012. http://articles.latimes.com/2012/jun/08/business/la-fi-restaurant-noise-20120504

[6] Buckley, C. (2012) Working or Playing Indoors, New Yorkers Face an Unabated Roar. The New York Times, 19 July 2012.

http://www.nytimes.com/2012/07/20/nyregion/in-new-york-city-indoor-noise-goes -unabated.html?pagewanted=all\&_r=3\&

[7] Hallock, B. (2012) Taking a Noise Snapshot at L.A. Restaurants. Los Angeles Times, 18 August 2012.

http://articles.latimes.com/2012/aug/18/food/la-fo-restaurant-noise-20120818

[8] Cornish, R. (2013) Din and Dinner: Are Our Restaurants Just Too Noisy? Goodfood, 6 August 2013.

http://www.goodfood.com.au/eat-out/news/din-and-dinner-are-our-restaurants-jus t-too-noisy-20130805-2r92e

[9] Bauer, M. (2013) A New Crop of Noisy Restaurants Threaten to Break the Sound Barrier. SFGate, 28 August 2013.

http://insidescoopsf.sfgate.com/blog/2013/08/28/a-new-crop-of-noisy-restaurants-t hreaten-to-break-the-sound-barrier/

[10] Bauer, M. (2014) Why Does Noise Continue to Grow in Restaurants? SFGate, 22 July 2014.

http://insidescoopsf.sfgate.com/blog/2014/07/22/why-does-noise-continue-to-grow -in-restaurants/

[11] Roncace, K. (2015) Are Philadelphia Restaurants Getting Too Loud? Reports Say Yes. NJ.com, 28 July 2015.

http://www.nj.com/entertainment/index.ssf/2015/07/are_philadelphia_restaurants_ getting_too_loud_repo.html

[12] Reader Comments (2015) The "Daunting” Din: Readers React to Noisy Restaurants. The New York Times, 9 September 2015.

https://www.nytimes.com/2015/09/10/dining/the-daunting-din-readers-react-to-no isy-restaurants.html

[13] Nielsen, N., Marschall, M., Santurette, S. and Jeong, C. (2016) Subjective Evaluation of Restaurant Acoustics in a Virtual Sound Environment. INTER-NOISE Confe- 
rence, August 2016.

[14] McCarron, A. and Tierney, K.J. (1989) The Effect of Auditory Stimulation on the Consumption of Soft Drinks. Appetite, 13, 155-159. https://doi.org/10.1016/0195-6663(89)90112-8

[15] Guéguen, N., Jacob, C., Le Guellec, H., Morineau, T. and Lourel, M. (2008) Sound Level of Environmental Music and Drinking Behavior: A Field Experiment with Beer Drinkers. Alcoholism: Clinical and Experimental Research, 32, 1-4. https://doi.org/10.1111/j.1530-0277.2008.00764.x

[16] Guéguen, N., Le Guellec, H. and Jacob, C. (2004) Sound Level of Background Music and Consumer Behavior: An Empirical Evaluation. Perceptual and Motor Skills, 99, 34-38. https://doi.org/10.2466/pms.99.1.34-38

[17] Blackwell, D.L., Lucas, J.W. and Clarke, T.C. (2014) Summary Health Statistics for U.S. Adults: National Health Interview Survey, 2012. Vital and Health Statistics, 10, $1-161$.

[18] Carroll, Y.I., Eichwald, J., Scinicariello, F., Hoffman, H.J., Deitchman, S., Radke, M.S., et al. (2017) Vital Signs: Noise-Induced Hearing Loss Among Adults-United States 2011-2012. Morbidity and Mortality Weekly Report, 66, 139-144.

[19] Goodson, S. and Hull, R. (2015) Hyperacusis. Audiology Information Series: Hyperacusis, American Speech-Language-Hearing Association.

[20] American Tinnitus Association. Understanding Facts and Causes Page. Washington DC. https://www.ata.org/understanding-facts/causes

[21] NIH (2014) Noise-Induced Hearing Loss. https://www.nidcd.nih.gov/health/noise-induced-hearing-loss

[22] Fritschi, L., Brown, L., Kim, R., Schwela, D. and Kephalopoulos, S. (2011) Burden of Disease from Environmental Noise-Quantification of Healthy Life Years Lost in Europe. WHO Regional Office for Europe, Copenhagen.

[23] Ohrstrom, E., Skanberg, A., Svensson, H. and Gidlof-Gunnarsson, A. (2006) Effects of Road Traffic Noise and the Benefit of Access to Quietness. Journal of Sound and Vibration, 295, 40-59. https://doi.org/10.1016/j.jsv.2005.11.034

[24] Babisch, W. (2011) Cardiovascular Effects of Noise. Noise Health, 13, 201-204. https://doi.org/10.4103/1463-1741.80148

[25] Pyko, A., Eriksson, C., Oftedal, B., Hilding, A., Ostenson, C., Krog, N.H., et al. (2015) Exposure to Traffic Noise and Markers of Obesity. https://doi.org/10.1136/oemed-2014-102516

[26] Flamme, G.A., Stephenson, M.R., Deiters, K., Tatro, A., VanGessel, D., Geda, K., et al. (2012) Typical Noise Exposure in Daily Life. International Journal of Audiology, 51, S3-S11.

[27] Neitzel, R.L., Gershon, R.R., McAlexander, T.P., Magda, L.A. and Pearson, J.M. (2012) Exposures to Transit and Other Sources of Noise among New York City Residents. Environmental Science \& Technology, 46, 500-508. https://doi.org/10.1021/es2025406

[28] Themann, C.L., Suter, A.H. and Stephenson, M.R. (2013) National Research Agenda for the Prevention of Occupational Hearing Loss-Part 1. Seminars in Hearing, 34, 145-207. https://doi.org/10.1055/s-0033-1349351

[29] National Academies of Sciences, Engineering, and Medicine (2016) Hearing Health Care for Adults: Priorities for Improving Access and Affordability. The National Academies Press, Washington DC.

[30] Musinguzi, D. (2010) The Impact of Restaurant Noise on Customers' Dining Expe- 
rience in Kowloon, Hong Kong. International Journal of Hospitality and Tourism Systems, 3, 80-85.

[31] Dewane, C. (2010) Hearing Loss in Older Adults-Its Effect on Mental Health. Social Work Today, 10, 18.

[32] Smith, P.A., Davis, A., Ferguson, M. and Lutman, M.E. (2000) The Prevalence and Type of Social Noise Exposure in Young Adults in England. Noise Health, 2, 41-56.

[33] Dixon, L. (2016) Speak Easy: Hearing the Views of Your Customers. Action on Hearing Loss.

https://www.actiononhearingloss.org.uk/-/media/ahl/documents/research-and-poli cy/reports/speakeasy-report.pdf

[34] Zagat Survey (2016) The State of American Dining in 2016.

[35] James, M. (2013) New York City Restaurant Survey Pet Peeves and Dining Stats. https://www.zagat.com/b/new-york-city/nyc-restaurants-survey-pet-peeves-and-din ing-stats\#1

[36] American Express (2015) Restaurant Briefing: Noises-The Disconnect with Diners.

https://knowledgecenter.americanexpress.com/restaurant-briefing-noises-disconnec t-diners/

[37] Rodgers, N. (2011) Chapter 9 in Why Noise Matters. Earthscan, New York.

[38] Lebo, C.P., Smith, M.F., Mosher, E.R., Jelonek, S.J., Schwind, D.R., Decker, K.E., et al. (1994) Restaurant Noise, Hearing Loss, and Hearing Aids. Western Journal of Medicine, 161, 45-49.

[39] Yu, T.S. and Wong, T.W. (2002) Occupational Noise Exposure and Hearing Impairment among Employees in Chinese Restaurants and the Entertainment Sector in Hong Kong. Hong Kong Health Services Research Committee Report 621016, Hong Kong.

[40] Hannah, L. (2004) Sound and the Restaurant Environment. New Zealand Acoustics, 17, 27-36.

[41] Ryberg, J.B. (2009) A National Project to Evaluate and Reduce High Sound Pressure Levels from Music. Noise Health, 11, 124-128. https://doi.org/10.4103/1463-1741.50698

[42] Samagwa, D., Mkoma, S.L. and Tungaraza, C. (2009) Investigation of Noise Pollution in Restaurants in Morogoro Municipality, Tanzania, East Africa. Journal of Applied Sciences and Environmental Management, 13, 29-33.

[43] To, W.M. and Chung, A.W.L. (2014) Noise in Restaurants: Levels and Mathematical Model. Noise Health, 16, 368-373. https://doi.org/10.4103/1463-1741.144412

[44] Kardous, C.A. and Shaw, P.B. (2016) Evaluation of Smartphone Sound Measurement Applications (Apps) Using External Microphones-A Follow-Up Study. The Journal of the Acoustical Society of America, 140, 186-192. https://doi.org/10.1121/1.4964639

[45] U.S. Environmental Protection Agency, Office of Noise Abatement and Control (1974) Information on Levels of Environmental Noise Requisite to Protect Public Health and Welfare with an Adequate Margin of Safety.

[46] World Health Organization (2009) Night Noise Guidelines for Europe. http://www.euro.who.int/en/health-topics/environment-and-health/noise/publicati ons

[47] National Institute for Occupational Safety and Health (1998) Criteria for a Recom- 
mended Standard: Occupational Noise Exposure. Cincinnati.

[48] Fink, D. (2017) What Is a Safe Noise Level for the Public? American Journal of Public Health, 107, 44-45. https://doi.org/10.2105/AJPH.2016.303527

[49] European Agency for Safety and Health at Work. Directive 2003/10/EC of the European Parliament and of the Council on the Minimum Health and Safety Requirements Regarding the Exposure of Workers to the Risks Arising from Physical Agents.

[50] (1990) Noise and Hearing Loss. NIH Consensus Statement, 8, 1-24.

[51] Le Prell, C.G., Hensley, B.N., Campbell, K.C., Hall, J.W. and Guire, K. (2011) Evidence of Hearing Loss in a Normally-Hearing College-Student Population. International Journal of Audiology, 50, S21-S31. https://doi.org/10.3109/14992027.2010.540722

[52] Rota-Donahue, C. and Levey, S. (2016) Noise-Induced Hearing Loss in the Campus. Hear Journal, 69, 38-39. https://doi.org/10.1097/01.HJ.0000484551.28667.81 